\title{
A Novel Multi-Criteria Decision Sorting Approach based on Chebyshev's Theorem for Supplier Classification Problem
}

\author{
Mohammad Azadfallah \\ Researcher, Business Studies and Development Office, \\ SAIPAYADAK (SAIPA after sales services organization), Tehran, Iran. \\ E mail: m.azadfallah@yahoo.com
}

\begin{abstract}
One of the interesting features of Multi-Criteria Decision Making/ Multiple Attribute Decision Making (MCDM/ MADM) is that a number of techniques that can be used to solve the same problem. In general, three common categories of decision problems are choice problem, ranking problem, and sorting problem. While, the issue of choice and ranking problems is more emphasized in MCDM/ MADM, but the literature weakly consider sorting problems. Several solutions for the above problem are suggested (i.e., Flow sort, AHP-Sort, ELECTRE Tri, etc.). Theoretically, there is no reason to be limited to these techniques. Hence, in this paper we propose a novel multi-criteria sorting method that is based on Chebyshev's theorem. More specifically, different from other studies on MCDM sorting problems, which put more emphasis on the extension of new models, this work attempts to present a general framework using the Chebyshev's inequality, to transform the results of conventional MCDM models from ranking format to sort mode. Finally, the proposed approach is compared with three existed models. Compared results show that the proposed method is efficient and the results are stable.
\end{abstract}

Keywords - MCDM/MADM; Classification; Sorting; Chebyshev's Theorem; Supplier Selection Problem.

\section{Introduction}

In the case of a single-criterion decision problem, the "best" solution is defined in terms of an "optimum solution" for which the criterion value is maximized (or minimized) when compared to any other alternative in the set of all feasibilities. In Multi Criteria [also often called Attribute] Decision Making (MCDM/ MADM) problems, however, as the optimums of each criterion do not usually point to the same alternative, a contradiction exists. The concept of an "optimum solution" does not usually exist in the context of conflicting, multiple criteria. Decision making in a MCDM problem is usually tantamount to choosing the best compromise solution. The "best solution" of an MCDM problem may be the "preferred (or best compromise) solution" or a "satisficing solution" (Ravindran, 2008).

MCDM/ MADM is an important component of modern decision science (Xu, 2015). According to Saaty and Daji's (2015) view, Since, the 1970s, MCDM research has developed quickly and has become a hot research topic because many complex practical decision problems involve multiple and conflicting criteria as well as multiple objectives. Generally, MCDM can be described as follows: the screening, prioritizing, ranking or selecting the alternatives based on human judgment from among a finite set of decision alternatives in terms of multiple usually conflicting criteria (Roszkowska, 2013).

The problem of MCDM can be generally classified into two categories, which are Multiple Attribute Decision Making (MADM) and Multiple Objective Decision
Making (MODM), depending on whether the selection problem or a design problem. MODM methods have decision variable values that are determined in a continuous or integer domain, with either an infinitive or a large number of choices, the best of which should satisfy the decision maker's (DMs) constraints and performance priorities. MADM methods, on the other hand, are generally discrete, with a limited number of predetermined alternatives (Rao, 2007). In this paper, we have used the terms MADM/ MCDM, and MCDA [Multi-Criteria Decision Analysis] interchangeably. The main steps in MCDM are the following (Roszkowska, 2011):

- Selection of the related criteria,

- generating alternatives,

- Evaluate alternatives in terms of criteria,

- Selection of the appropriate MCDM models,

- Accept one alternative as "optimal" (preferred),

- If the final solution is not accepted, gather new information and go to the next iteration of multi-criteria optimization.

A MADM problem with $m$ alternatives and $n$ attributes can be expressed in matrix format as follows (Yue, 2013 ${ }_{\mathrm{a}}$ ):

$$
\mathrm{X}=\left(\mathrm{x}_{\mathrm{ij}}\right)_{\mathrm{m} . \mathrm{n}}=\begin{array}{c|cccc}
\mathrm{A}_{1} & \mathrm{U}_{1} & \mathrm{U}_{2} & \ldots & \mathrm{U}_{\mathrm{n}} \\
\mathrm{A}_{2} & \mathrm{x}_{21} & \mathrm{x}_{12} & \ldots & \mathrm{x}_{1 \mathrm{n}} \\
\cdot & \cdot & \cdot & . & \cdot \\
\cdot & \cdot & \cdot & \cdot & \cdot \\
\cdot & \cdot & \cdot & \cdot & \cdot \\
\mathrm{A}_{\mathrm{m}} & \mathrm{x}_{\mathrm{m} 1} & \mathrm{x}_{\mathrm{m} 2} & \ldots & \mathrm{x}_{\mathrm{mn}}
\end{array}
$$

$\mathrm{W}_{\mathrm{j}}=\left(\mathrm{w}_{1}, \mathrm{w}_{2} \ldots \mathrm{w}_{\mathrm{n}}\right)$. 
Where, $A_{1}, A_{2}, \ldots, A_{m}$ are feasible alternatives, $U_{1}, U_{2}, \ldots$, $\mathrm{U}_{\mathrm{n}}$ are evaluation attributes, $\mathrm{X}_{\mathrm{ij}}$ is the performance rating of alternative $A_{i}$ under attribute $U_{j}$, and $W_{j}$ is the weight of attribute $\mathrm{U}_{\mathrm{j}}$.

On the other side, in 1996, Roy (1996) identifies four different references problematic, for which MCDA may be useful:

- The choice problematic - presents the problem in terms of choosing one "best" action.

- The sorting problematic - presents the problem in terms of placing actions in categories that are defined in terms of the eventual fate of the actions.

- The ranking problematic - presents the problem in terms of ranking the actions.

- The description problematic - presents the problem in terms of describing the actions and their consequences.

Furthermore, according to Ishizaka and Nemery (2013) and Belton and Stewart (2002), additional problem types have also been proposed in the MCDA community, Elimination problem, Design problem, and Elicitation problem; value measurement models, goal, aspiration or reference level model, and Outranking models, respectively. However, Mcmmah, Turion, and Rolland (2014) believe that, three major types of Multi-Criteria Decision Making problems could be treated using MCDM methods: choice, ranking and sorting. Meanwhile, choice and ranking problems are the ones most commonly considered in Operation research/ Management science and MCDA (Doumpos \& Zopounidis, 2018), therefore, the literature weakly consider sorting problem. The present paper addresses this problem.

Multiple-Criteria Sorting Problem is assigning a set of alternatives into predefined, homogeneous and ordinal groups via a criteria aggregation model in the existence of multiple criteria (Karasakal \& Aker, 2017). Karsu (2016) believe that, many practical problems involve the assignment of alternatives into predefined homogeneous groups. From a multi-criteria point of view, this problem can be handled using Multi-Criteria Sorting or Classification techniques. Multi-Criteria Sorting refer to the cases where the groups are defined in an ordinal way starting from the ones including the most preferred alternatives to the ones including the least preferred alternatives while classification refers to the cases where these groups are in a nominal way. Further, according to Sabokbar, Hosseini, Banaitis, and Banaitiene (2016), Multi-Criteria Sorting methods differ from standard classification in two main features: (1) categories are predefined and ordered, and (2) the sorting model integrates preferences of a decision maker.

Following Chen (2006) three types of classification problems can be distinguished: (1) screening; reduce a large set of alternatives to a smaller set that most likely contains the best choice, (2) sorting; arrange the alternatives into a few groups in preference order, so that the DM can manage them more effectively, and (3) nominal classification; assign alternatives to nominal groups structured by the DM, so that the number of groups, and the characteristics of each group, seen appropriate to the DM. the concern here is with the second type of classification.

In general, The Multi-Criteria Sorting problem is as follows:

A finite set of alternatives $A=\left\{a_{1}, a_{2}, \ldots, a_{m}\right\}$ is evaluated on a family of $g=\left\{g_{1}, g_{2}, \ldots, g_{n}\right\} n$ criteria. Let be a set of alternatives index $I ; I=\{1,2, \ldots, m\}$ and a set of criteria index $J ; J=\{1,2, \ldots, n\}$. Given an alternative $a_{i}$, $\mathrm{g}_{\mathrm{j}}\left(\mathrm{a}_{\mathrm{i}}\right)$ shows the performance of alternative $\mathrm{a}_{\mathrm{i}}$ in criterion $\mathrm{j}$. the DM wants to sort the options into $q$ classes. Let $C_{k}$ denote class $\mathrm{k}$ where $\mathrm{C}_{1}$ is the most preferred and $\mathrm{C}_{\mathrm{q}}$ the least preferred. Let the index set of the classes be $\mathrm{k}=\{1$, 2, ..., q $\}$ (Karsu, 2016). In addition, several MCDA methods have been developed in order to deal with sorting problems, which briefly is as follow (Sobrie, 2016):

- ELECTRE Tri (and two variants; majority rule sorting model and non-compensatory sorting model) ELECTRE Tri is an outranking sorting procedure proposed by $\mathrm{Yu}$ (in 1992). The method aims at assigning each alternative of a set to a category selected among a set of pre-defined and ordered categories.

- Additive Value Function Sorting Model - Additive Value Function Sorting (AVF-Sort) Models belong to the family of MAVT methods. In some types of models, a numeric score is assigned to each alternative.

- Other Multiple Criteria Decision Analysis Sorting methods

$\begin{array}{ll}\circ & \text { Trichotomic segmentation } \\ \circ & \text { nTOMIC } \\ \circ & \text { PROAFTN } \\ \circ & \text { ELECTRE Tri-C and ELECTRE Tri-nC } \\ \circ & \text { Flow Sort } \\ \circ & \text { TOMASO }\end{array}$

Moreover, in recent years, many new MCDM sorting models have been developed. For instance, AHP-Sort (Ishizaka, Pearman, \& Nemery, 2012), TOPSIS-Sort (Sabokbar, Hosseini, Banaitis, and Banaitiene, 2016), AHP-K-GDSS [AHP-based group sorting method] (Ishizaka, Lolli, Ganberini, Rimini, \& Balugani, 2017), and so on.

On the other side, in a period of global sourcing, business's success often hinges on the most appropriate 
selection of its partners and suppliers. Specifically, suitable supplier's selection is one of the essential policies for improving the quality of output of any organization, which has a direct impact on the company's competitiveness and reputation (Kamal, Gupta, \& Raina, 2018). In fact, the suppliers cause directly the success or fail of an organization (Tabar \& Charkhgard, 2012). Supplier selection is the process by which suppliers are reviewed, evaluated, and chosen to become part of the company's supply chain (Roostaee, Izadikhah, Lotfi, \& Malkhalifeh, 2012). Reduce purchasing risk, maximize overall value to the purchaser, and build a long-term, reliable relationship between buyers and suppliers are the objectives that supplier selection follows (Arabzad, Ghorbani, Razmi, \& Shirouyehzad, 2014).

Company's frequently misunderstand the supplier selection problem as a single-criterion decision making problem, taking into account only cost factors when making decisions. This method is inefficient, so there are other quantitative and qualitative factors that need to be considered. Tradeoffs between multiple and conflicting objectives have to be made in order to select the best supplier (Frej, Roselli, Almedia, \& Almedia, 2017). Since this selection process mainly involves the evaluation of different criteria and various supplier attributes, it can be considered as a MCDM problem (Ayhan, 2013). Therefore, supplier selection is a multi-criteria problem and is usually treated using MCDM techniques (Seifbarghy, Gilklayeh, \& Alidoost, 2011).

According to Amidan, Ferryman, and Cooley (2005), Chebyshev's inequality (otherwise known as Chebyshev's theorem) was designed to determine the lower bound of the percentage of data that are between $k$ numbers of standard deviations from the mean. In the case of data with a normal (bell-shaped) distribution, it is known that about 95\% of the data will fall within two standard deviations from the mean. This means that you would expect to see about $5 \%$ of the data outside two standard deviations from the mean. When the data distribution is unknown, Chebyshev's inequality can be used, as shown by:

$$
\mathrm{P}\left(|\mathrm{X}-\mu| \leq \mathrm{K} \sigma \geq\left(1-1 / \mathrm{K}^{2}\right)\right.
$$

Where $x$ represents the data, $\mu$ is the data mean, $\sigma$ is the standard deviation of the data, and $k$ represents the number of standard deviations from the mean. While no assumptions have been made about the distribution, the observations are expected to be independent of each other. From equation (1), it can be shown that at least $75 \%(3 / 4)$ of the data would fall within two standard deviations $(K=2)$ from the mean. Chebyshev's inequality gives a lower bound for the percentage of data that is within a certain number of standard deviations from the mean, it does not depend on any knowledge of how the data is distributed. In general, many MADM/ MCDM/ MCDA approaches have been used to solve the supplier selection problem. However, most of them are focused only the ranking and choice problems. In this paper, a sorting approach based on Chebyshev's theorem is developed and used for sorting suppliers in supply chain environment.

The paper is organized as follows. In section 2, the literature is discussed. In section 3 and section 4 , the research design and the proposed approach is discussed, respectively. Numerical example is provided in section 5 . The findings and the conclusion of the paper is presented in section 6 and section 7 .

\section{Literature Review}

In the literature, Multi-criteria sorting has been applied in various fields. According to many author's (see, for instance, [Zopounidis \& Dumpos, 2002; and Chen, 2006]), medicine, pattern recognition, human resource management, production systems, management and technical diagnosis, marketing, environmental and energy management, ecology, financial management and economics, could be referred as an example. Zopounidis and Dumpos (2002) believe that, this wide range of realworld applications of the classification/ sorting problem has constitute a major motivation for researchers in developing methodologies for constructing classification/ sorting models. In this section, we assessed just those ones, which were based on sorting models. For instance, Mousseau and Slowinski (1998) proposed an interactive approach that infers the parameters of an ELECTRE Tri model from assignment examples. As noted earlier, Zopounidis and Dumpos (2002) gave a comprehensive literature review of multi-criteria sorting models. Dias and Mousseau (2003) provided an interactive robustness analysis and parameters inference for multi-criteria sorting problems (IRIS), and then designed a decision support system (DSS) to sort the options. Lourenco and Costa (2004) developed an interactive "branch and bound like" technique to progressively build the non dominated set, then combined with ELECTRE Tri method to sort identified non dominated solutions. Araz and Ozkarahan (2005) extended a new sorting procedure in financial classification problems, based on methodological framework of PROMETHEE method. Bouyssou and Marchant (2007a) provided an axiomatic analysis of the partitions of alternatives into two categories. In addition, in other works Bouyssou and Marchant $\left(2007_{\mathrm{b}}\right.$ ) presented an axiomatic analysis of what we call non-compensatory sorting models, with or without veto effects. Damart, Dias, and Mousseau (2007) emphasized the situation in which groups intend to collaboratively develop a multi-criteria evaluation model to sort options within classes. Dias, Figueira, and Roy (2008) proposed a new method within the ELECTRE framework. The (ELECTRE Tri-C) method deals with sorting problems where the pre-defined and

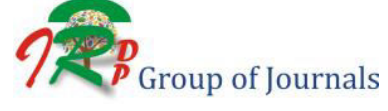


ordered categories are based on central reference actions instead of boundary actions. Rocha and Dias (2008) presented a Progressive Assisted sorting algorithm (PASA) based on a multi-criteria evaluation ELECTRE-type method. Tervone, Figueira, Lahdelma, Dias, and salminen (2009) invented a method, SMAA-Tri that is based on Stochastic Multi-criteria Acceptability Analysis (SMAA) for identifying the stability of parameters in sorting problems. Dias, Figueira, and Roy (2012) identified ELECTRE Tri-nC, a method that consider several preference actions for characterizing each category. Ishizaka, Pearman, and Nemery (2012) presented an AHP based method for sorting problems. Memmah, Turion, and Rolland (2014) proposed a multi-criteria sorting method to select virtual peach ideotypes. Ishizaka and Nemery (2014) extended ELECTRE Sort, a new method that is possible to consider an unlimited number of criteria in order to assign machines to incomparable strategies. Corrente, Greco, and Slowinski (2016) applied the multiple criteria hierarchy process to the ELECTRE Tri methods. Karsu (2016) developed three sorting algorithms that are different from the ones in the current literature in the sense that they apply to cases where the DMs preference relation satisfies anonymity and convexity properties. The first two procedures are based on additive utility function assumption and the third one is based on the concept of symmetric Choquet integral. Sabokbar, Hosseini, Banaitis, and Banaitiene (2016) introduced a new TOPSIS-based sorting method for sorting actions. Sobrie (2016) urbanized a Meta heuristic model to learn the parameters of a MCDA sorting method, and called it the majority rule sorting (MRSort) model. Ishizaka, Lolli, Gamberini, Rimini, and Balugani (2017) defined a new AHP-based group sorting method with the aim of classifying a set of alternatives into a predefined number of ordered classes, without recourse to limiting profile defined by decision makers. Karaskal and Aker (2017) developed a multi-criteria sorting methods based on Data Envelopment Analysis (DEA), to evaluate Research and Develop (R\&D) projects. Finally, Pelissari, Amor, and Oliveira (2019) proposed a sorting MCDM model for pharmaceutical supplier selection under multiple uncertainties and heterogeneous information. Here, it should be noted that during our review of the literature, no model was found that used a combination of methods (MCDM and Chebyshev's theorem) proposed in this paper. Meanwhile, most methods emphasis, only the ranking and choice problem, the focus of this article is on sorting problems.

\section{Research Design}

A sorting problem aims to assign each alternative into one of the predefined ordered classes (Ishizaka, Lolli, Gamberini, Rimini, \& Balugani, 2017). The assignment of alternatives (observation/ objects) into predefined homogenous groups is a problem of major practical and research interest (Zopounidis \& Dumpos, 2002). According to Karsu (2016), classification/ sorting problems have applications in many areas including but not limited to medicine, pattern recognition, human resource management, financial management and economics (more on this can be found in Zopounidis \& Dumpos, 2002). Chen (2006) believe that, this rich range of potential real world applications has encouraged researchers to develop innovative methodologies for sorting.

In the literature, several solutions for the above problem are proposed. Although, theoretically there is no reason to be limited to these techniques. Therefore, in this paper we propose a novel multi-criteria sorting method that is based on Chebyshev's theorem. More specifically, different from other studies on MCDM sorting problems, which put more emphasis on the extension of new models, this work attempts to suggest a general framework using the Chebyshev's inequality to transform the results of traditional MCDM methods from ranking format to sort mode. However, Memmah, Turion, and Rolland (2014) believe that, many MCDM methods are dedicated to the ranking or choosing problems. Even if it is always possible to use a ranking method to sort alternatives by the addition of thresholds for example, it is clear that MAUT (Multiple Attribute Utility Theory) methods are more efficient to rank alternatives than to sort them. Conversely, special models, such as ELECTRE Tri, where developed to sort the alternatives and then should be used preferably. We think it is not a good reason to ignore the use of the ranking and choosing models potential capacities in the sorting sectors. Meanwhile, it deprives us for further use of the existing models. Therefore, the aim of this paper is to change the conventional supplier selection methods by shifting the emphasis from using a ranking and choosing approach to using sorting methods. So, it allows manufacturer to develop a scoring system (Chebyshev'sbased model) to partitioning suppliers into best performance/ worst performance sets (Figure 1). Therefore, suppliers are sorted into predefined ordered from the best performance to worst performance categories.

\footnotetext{
- Decreasing auditing

- Providing loans to suppliers

- Introducing supplier as a Benchmark to network

.Increasing auditing

- Reducing price paid to the Suppliers

- Establish training course for Suppliers
}

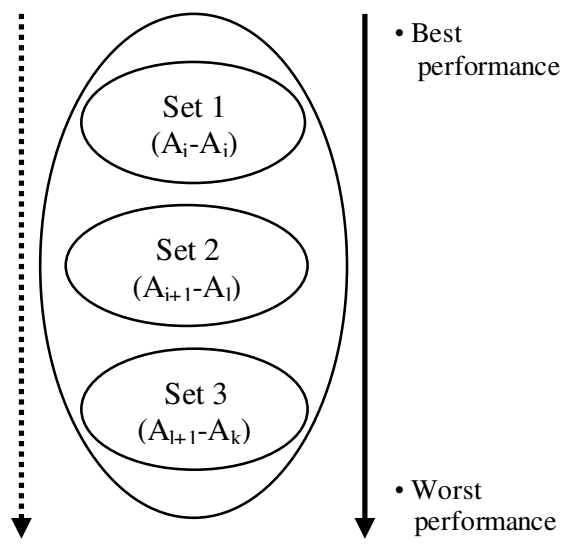

Fig.1: Classify suppliers into categories 


\section{Proposed Method}

According to the view point proposed by Zopounidis and Doumpos (2002), the wide range of real-world applications of the classification/ sorting problem has constitute a major motivation for researchers in developing methodologies for constructing classification/ sorting models. It is the aim of this paper. Before continuing, it is necessary to define deviation standard. According to Dunn (2001), the symbol for the population variance is $\sigma^{2}$, or "lower case sigma squared". The formula for determining the variance of a population is (Eq. 2):

$\sigma^{2}=\sum(\mathrm{X}-\mu)^{2} / \mathrm{N}$

That is, the population variance is the sum of the squared deviations between all observations $(\mathrm{X})$ in the population and the mean of the population $(\mu)$, which is them divided by the total number of available observations.

\subsection{Chebyshev's Theorem}

The Russian mathematician P. L. Chebyshev (18211894) discovered that the fraction of the area between any two values symmetric about the mean is related to the standard deviation. As respects the area under a probability distribution curve or in a probability histogram adds to 1 , the area between any two numbers is the probability of the random variable assuming a value between these numbers. The following theorem gives a conservative estimate of the probability that a random variable assumes value within $\mathrm{K}$ standard deviations of its mean for any real number $\mathrm{K}$.

Theorem 1: The probability of any random variable $\mathrm{X}$ will assume a value within $\mathrm{K}$ standard deviations of the mean is at least $1-1 / \mathrm{k}^{2}$,

$\mathrm{P}(\mu-\mathrm{K} \sigma<\mathrm{X}<\mu+\mathrm{K} \sigma) \geq 1-1 / \mathrm{k}^{2}$

For $\mathrm{k}=2$, the theorem states that the random variable $\mathrm{X}$ has a probability of at least $1-1 / 2^{2}=3 / 4$ of falling within two standard deviations of the mean. That is, three-fourth or more of the observations of any distribution lie in the interval $\mu^{+}-2 \sigma$. In a similar way, the theorem says that at least eight-ninths of the observations of any distribution fall in the interval $\mu^{+} .3 \sigma$ (Walpole, Myers, Myers, and Ye, 2016).

The proposed method consists of the following steps:

1. Establish the decision matrix $x=\left(x_{i j}\right)_{n . m}$,

2. Determine the weights of criteria - In the literature, there are several techniques can be applied to obtain the criteria weights (i.e., Entropy, Eigenvector method, etc.). On the other hand, according to Birnbaum (1998), several researchers have discussed that the identical weight rule is often a highly accurate predigestion of the decision making process. It is the aim of this paper. Therefore, $\mathrm{W}_{\mathrm{j}}=1 / \mathrm{n}$,

3. Solve the decision problem with one of the existing MCDM models (TOPSIS, AHP, VIKOR, etc.). Notice, the decision model used in this paper is the TOPSIS method (as discussed latter in this paper),

4. Determine the variance $\left(\sigma^{2}\right)$ and the mean $(\mu)$ of a MCDM model results (Eq. 2, and step 3), Then determined the MCDM model results standard deviations $(\sigma)$, with below formula as follows:

$\Sigma=\sqrt{ } \sigma^{2}$

5. Choose one of the triple suggested Chebyshev's-based formulas (Eq. 3) proposed in this paper (Eq. 5-7), based on the standard deviation levels (in other words, falling within one, two, and three standard deviations of the mean: $\sigma=1, \sigma=2$, and $\sigma=3$ respectively),

5.1. for $\sigma=1$ :

$$
\begin{gathered}
\mathrm{X}>\mu_{\mathrm{x}}+1 \sigma_{\mathrm{x}} \\
\mu_{\mathrm{x}} \leq \mathrm{X} \leq \mu_{\mathrm{x}}+1 \sigma_{\mathrm{x}} \\
\mu_{\mathrm{x}}-1 \sigma_{\mathrm{x}} \leq \mathrm{X}<\mu_{\mathrm{x}} \\
\mathrm{X}<\mu_{\mathrm{x}}-1 \sigma_{\mathrm{x}}
\end{gathered}
$$

5.2. for $\sigma=2$ :

$$
\begin{gathered}
\mathrm{X}>\mu_{\mathrm{x}}+2 \sigma_{\mathrm{x}} \\
\mu_{\mathrm{x}}+1 \sigma_{\mathrm{x}} \leq \mathrm{X} \leq \mu_{\mathrm{x}}+2 \sigma_{\mathrm{x}} \\
\mu_{\mathrm{x}} \leq \mathrm{X}<\mu_{\mathrm{x}}+1 \sigma_{\mathrm{x}} \\
\mu_{\mathrm{x}}-1 \sigma_{\mathrm{x}} \leq \mathrm{X}<\mu_{\mathrm{x}} \\
\mathrm{X}<\mu_{\mathrm{x}}-1 \sigma_{\mathrm{x}}
\end{gathered}
$$

5.3. for $\sigma=3$ :

$$
\begin{gathered}
\mathrm{X}>\mu_{\mathrm{x}}+3 \sigma_{\mathrm{x}} \\
\mu_{\mathrm{x}}+2 \sigma_{\mathrm{x}} \leq \mathrm{X} \leq \mu_{\mathrm{x}}+3 \sigma_{\mathrm{x}} \\
\mu_{\mathrm{x}}+1 \sigma_{\mathrm{x}} \leq \mathrm{X}<\mu_{\mathrm{x}}+2 \sigma_{\mathrm{x}} \\
\mu_{\mathrm{x}} \leq \mathrm{X}<\mu_{\mathrm{x}}+1 \sigma_{\mathrm{x}} \\
\mu_{\mathrm{x}}-1 \sigma_{\mathrm{x}} \leq \mathrm{X}<\mu_{\mathrm{x}} \\
\mathrm{X}<\mu_{\mathrm{x}}-1 \sigma_{\mathrm{x}}
\end{gathered}
$$

Notice; upper bound is higher value than the lower bound.

6. Determine the upper bound and lower bound values, by using proposed method (Chebyshev's-based formula; Eq. 5, 6, and 7, as a reference profile),

7. Compare the obtained values of alternatives (or suppliers) (step 3) with the reference profile (step 6). Then, assigning each alternative to one of the predefined categories.

\subsection{TOPSIS Technique}

Technique for Order Preference by Similarity to the Ideal Solution (TOPSIS) is a Multi-Criteria Decision Making technique, which was developed by Hwang and 
Yoon (1981). According to Fallahpour (2016), TOPSIS is a MCDM-based model, which has been widely used for decision making and ranking in different fields of science. Dizaji and Khanmohammadi (2016) believe that, one of the most common ways MCDM is TOPSIS. According to Yue $\left(2013_{\mathrm{b}}\right)$, the underlying logic of TOPSIS is to define an ideal solution and negative ideal solution. The ideal solution is one that maximizes the benefit attributes and minimizes the cost attributes. In short, the ideal solution comprise of all best attribute values; whilst as the negative ideal solution is compound of all worst attribute values. The optimal alternative is the one, which has the shortest distance from the positive ideal solution and the farthest distance from the negative ideal solution. In sum, the process for the TOPSIS algorithm beginning with forming the decision matrix representing the satisfaction value of each criterion with each alternative. Next, the matrix is normalized with a desirable normalizing procedure, and the values are multiplied by the criteria weights. Subsequently, the positive-ideal and negative-ideal solutions are calculated, and the distance of each alternative to these solutions is calculated with a Euclidean distance measure. Eventually, the alternatives are ranked based on their relative closeness to the ideal solution (Roszkowska, 2011). In addition, the four main advantages of TOPSIS are (Shih, Shyur, \& Lee, 2007):

i) A profound logic that demonstrates the rationality of human choice,

ii) A scalar value that is calculated for both the best and worst alternatives simultaneously,

iii) A simple computational process that can be easily programmed for a spread sheet,

iv) The performance measures of all alternatives on attributes can be visually displayed on a polyhedron, at least for any two dimensions.

Nevertheless, the steps of the TOPSIS are given as follows (Tayeb, Ahcene, Omar, \& Mouloud, 2007):

Step 1: Construct the normalized decision matrix.

Normalized decision matrix $X-\left\{x_{i j}\right]_{m . n}$ by Eq. (8).

$r_{i j}=X_{i j} / \sqrt{ } \sum X_{i j}^{2}$ for $i=1, \ldots, m ; j=1, \ldots, n$.

Step 2: Construct the weighted normalized decision matrix.

Construct the weighted normalized decision matrix $\mathrm{V}_{\mathrm{ij}}$ by Eq. (9). Further, Assume we have a set of weights for each criteria wj for $\mathrm{j}=1, \ldots, \mathrm{n}$. multiplies each column of the normalized decision matrix by its associated weight. An element of the new matrix is: $V_{i j}=w_{j} r_{i j}$

Step 3: Determine the ideal and negative ideal solutions.

Determine the positive ideal solution (PIS) and negative ideal solutions (NIS) by Eqs. (10) and (11).
PIS: $A^{*}=\left\{v_{1}^{*}, \ldots, v_{n}{ }^{*}\right\}$

where, $V_{\mathrm{j}}^{*}=\left\{\max \left(\mathrm{v}_{\mathrm{ij}}\right)\right.$ if $\mathrm{j} \varepsilon \mathrm{J}$; $\min \left(\mathrm{v}_{\mathrm{ij}}\right)$ if $\left.\mathrm{j} \varepsilon \mathrm{J}^{\prime}\right\}$

NIS: $A^{-}=\left\{\mathrm{v}_{1}^{-}, \ldots, \mathrm{v}_{\mathrm{n}}^{-}\right\}$

where, $V_{j}^{*}=\left\{\min \left(V_{i j}\right)\right.$ if $j \varepsilon J ; \max \left(V_{i j}\right)$ if $\left.j \varepsilon J^{-}\right\}$

Step 4: Calculate the separation measures for each alternative.

Calculate the separation measures for each alternative by Eqs. (12) and (13). The separation from the PIS:

$\mathrm{S}_{\mathrm{i}}^{*}=\left[\sum\left(\mathrm{v}_{\mathrm{j}}^{*}-\mathrm{v}_{\mathrm{ij}}\right)^{2}\right]^{\wedge^{1 / 2}} \mathrm{i}=1, \ldots, \mathrm{m}$.

Similarly, the separation from the NIS:

$\mathrm{S}_{\mathrm{i}}^{-}=\left[\sum\left(\mathrm{v}_{\mathrm{j}}^{-}-\mathrm{v}_{\mathrm{ij}}\right)^{2}\right]^{\wedge 1 / 2} \mathrm{i}=1, \ldots, \mathrm{m}$.

Step 5: Determine the relative closeness to the ideal solution.

Determine the relative closeness to the ideal solution $\left(\mathrm{C}_{\mathrm{i}}^{*}\right)$ by Eq. (14). $\mathrm{C}_{\mathrm{i}}^{*}=\mathrm{S}_{\mathrm{i}}^{-} / \mathrm{S}_{\mathrm{i}}^{*}+\mathrm{S}_{\mathrm{i}}^{-}, \quad 0<\mathrm{C}_{\mathrm{i}}^{*}<1$

Step 6: Rank alternatives in terms of their relative closeness's.

Rank alternatives by maximizing the ratio in step 5. Select the option with $\mathrm{C}_{\mathrm{i}}$ * closest to 1 .

\section{Numerical Example}

The following example involves a multi-criteria supplier selection problem in a supply chain environment to illustrate the implementation of our proposed models. Assume that there are ten alternatives (or suppliers; S1, $\mathrm{S} 2, \ldots, \mathrm{S} 10)$, and three criteria $(\mathrm{C} 1=$ shorter lead times, $\mathrm{C} 2=$ higher quality, and $\mathrm{C} 3=$ reduce cost). As you see, the performance values is shown in table 1 (step 1). In addition, equal weights have been initially allocated to all the criteria. Thus, $\mathrm{Wj}=(0.333,0.333$, and 0.333$)$ (step 2$)$.

Table 1. Performance Values

\begin{tabular}{|l|l|c|c|c|}
\hline \multicolumn{2}{|c|}{} & \multicolumn{3}{|c|}{ Criteria } \\
\cline { 2 - 5 } \multicolumn{2}{|c|}{} & $\mathrm{C}_{1}{ }^{*}$ & $\mathrm{C}_{2}{ }^{*}$ & $\mathrm{C}_{3}{ }^{*}$ \\
\hline \multirow{7}{*}{ Alternative } & $\mathrm{S} 1$ & 7 & 58 & 31 \\
\cline { 2 - 5 } & $\mathrm{S} 2$ & 3 & 97 & 21 \\
\cline { 2 - 5 } & $\mathrm{S} 3$ & 9 & 79 & 23 \\
\cline { 2 - 5 } & $\mathrm{S} 4$ & 5 & 57 & 18 \\
\cline { 2 - 5 } & $\mathrm{S} 5$ & 3 & 88 & 34 \\
\cline { 2 - 5 } & S6 & 5 & 89 & 25 \\
\cline { 2 - 5 } & S7 & 1 & 75 & 27 \\
\cline { 2 - 5 } & S8 & 5 & 84 & 26 \\
\cline { 2 - 5 } & S9 & 9 & 71 & 25 \\
\cline { 2 - 5 } & S10 & 7 & 93 & 17 \\
\hline
\end{tabular}

*. Benefit-type criteria, and $\mathrm{W}_{\mathrm{j}}=(0.333,0.333$, and 0.333$)$. 
In this section, with no intention to describe the whole procedure, we shall only point to the final results. Nevertheless, to solve this example using the traditional TOPSIS method (step 3), we go through the following steps:

\section{Calculate the normalized decision matrix}

$\mathrm{R}_{\mathrm{ij}}=\left|\begin{array}{ccc}0.372 & 0.229 & 0.389 \\ 0.159 & 0.383 & 0.263 \\ 0.478 & 0.312 & 0.289 \\ 0.266 & 0.225 & 0.226 \\ 0.159 & 0.347 & 0.427 \\ 0.266 & 0.351 & 0.314 \\ 0.053 & 0.296 & 0.339 \\ 0.266 & 0.331 & 0.326 \\ 0.478 & 0.280 & 0.314 \\ 0.372 & 0.367 & 0.213\end{array}\right|$

2. Calculated the weighted decision matrix (as noted earlier; $W_{j}=(0.333,0.333$, and 0.333). the weighted decision matrix is then:

$\mathrm{V}_{\mathrm{ij}}=\left|\begin{array}{ccc}0.124 & 0.076 & 0.129 \\ 0.053 & 0.127 & 0.088 \\ 0.159 & 0.104 & 0.096 \\ 0.088 & 0.075 & 0.075 \\ 0.053 & 0.116 & 0.142 \\ 0.083 & 0.117 & 0.104 \\ 0.018 & 0.098 & 0.113 \\ 0.088 & 0.110 & 0.109 \\ 0.159 & 0.093 & 0.104 \\ 0.124 & 0.122 & 0.071\end{array}\right|$

\section{Determine the ideal and negative-ideal solutions}

$\mathrm{A}^{*}=\left\{\mathrm{v}_{1}{ }^{*} \ldots \mathrm{v}_{\mathrm{n}}{ }^{*}\right\}$; where $\mathrm{V}_{\mathrm{j}}{ }^{*}=\left\{\max \left(\mathrm{v}_{\mathrm{ij}}\right)\right.$ if $\mathrm{j} \varepsilon \mathrm{J} ; \min \left(\mathrm{v}_{\mathrm{ij}}\right)$ if $\left.\mathrm{j} \varepsilon \mathrm{J}^{\prime}\right\}$;

$\mathrm{A}^{*}=(0.159,0.127,0.142)$

$A^{-}=\left\{v_{1}^{-} \ldots v_{n}^{-}\right\} ;$where, $V_{j}^{-}=\left\{\min \left(v_{i j}\right)\right.$ if $j \varepsilon J ; \max (v i j)$ if $\left.\mathrm{j} \varepsilon \mathrm{J}^{\prime}\right\}$

$\mathrm{A}^{-}=(0.018,0.075,0.071)$

\section{Calculated the separation measures}

$\mathrm{S}_{\mathrm{i}}{ }^{*}=\left[\Sigma_{\mathrm{j}=1}{ }^{3}\left(\mathrm{v}_{\mathrm{j}}{ }^{*}-\mathrm{v}_{\mathrm{ij}}\right)^{2}\right]^{\wedge 1 / 2}, \quad \mathrm{i}=1,2,3,4,5,6,7,8,9,10$.

$\mathrm{S}_{1}^{*}=0.064, \mathrm{~S}_{2}=0.119, \mathrm{~S}_{3}=0.052, \mathrm{~S}_{4}=0.111, \mathrm{~S}_{5}=0.107$, $\mathrm{S}_{6}=0.081, \mathrm{~S}_{7}=0.147, \mathrm{~S}_{8}=0.080, \mathrm{~S}_{9}=0.051$, and $\mathrm{S}_{10}=0.081$,

$\mathrm{S}_{\mathrm{i}}^{-}=\left[\Sigma_{\mathrm{j}=1}^{3}\left(\mathrm{v}_{\mathrm{j}}^{-}-\mathrm{v}_{\mathrm{ij}}\right)^{2}\right]^{\wedge 1 / 2}, \quad \mathrm{i}=1,2,3,4,5,6,7,8,9,10$. $\mathrm{S}_{1}{ }^{-}=0.121, \mathrm{~S}_{2}{ }^{-}=0.066, \mathrm{~S}_{3}{ }^{-}=0.147, \mathrm{~S}_{4}{ }^{-}=0.071, \mathrm{~S}_{5}{ }^{-}=0.089$, $\mathrm{S}_{6}{ }^{-}=0.089, \mathrm{~S}_{7}{ }^{-}=0.048, \mathrm{~S}_{8}{ }^{-}=0.088, \mathrm{~S}_{9}^{-}=0.147$, and $\mathrm{S}^{-}$ ${ }_{10}=0.116$.

\section{Calculated the relative closeness to the ideal solution}

$\mathrm{C}_{\mathrm{i}}^{*}=\mathrm{S}_{\mathrm{i}} / \mathrm{S}_{\mathrm{i}}^{*}+\mathrm{S}_{\mathrm{i}}^{-}$,

$\mathrm{C}_{1}{ }^{*}=0.656$

$\mathrm{C}_{2}{ }^{*}=0.355$

$\mathrm{C}_{3}{ }^{*}=0.739$

$\mathrm{C}_{4}{ }^{*}=0.391$

$\mathrm{C}_{5}{ }^{*}=0.455$

$\mathrm{C}_{6}{ }^{*}=0.524$

$\mathrm{C}_{7}{ }^{*}=0.246$

$\mathrm{C}_{8}{ }^{*}=0.522$

$\mathrm{C}_{9}{ }^{*}=0.743$

$\mathrm{C}_{10}{ }^{*}=0.594$.

6. Rank the preference order.

Ultimately, According to the descending Order of $\mathrm{C}_{\mathrm{i}}^{*}$, the preference order is as follows:

$\mathrm{S} 9>\mathrm{S} 3>\mathrm{S} 1>\mathrm{S} 10>\mathrm{S} 6>\mathrm{S} 8>\mathrm{S} 5>\mathrm{S} 4>\mathrm{S} 2>\mathrm{S} 7$ 0.7430 .7390 .6560 .5940 .5240 .5220 .4550 .3910 .3550 .246

In continuation, the population variance $\left(\sigma_{\mathrm{x}}^{2}\right)$ and mean $\left(\mu_{\mathrm{x}}\right)($ step 4$)$ is given by:

$\mu_{\mathrm{x}}=\sum \mathrm{X} / \mathrm{N}=$

$(0.656+0.355+0.739+0.391+0.455+0.524+0.246+0.522+0$. $743+0.594) / 10=0.522$,

$\sigma_{\mathrm{x}}^{2}=\sum(\mathrm{X}-\mu)^{2} / \mathrm{N}=\left((0.656-0.522)^{2}+(0.355-0.522)^{2}+\right.$ $(0.739-0.522)^{2}+(0.391-0.522)^{2}+(0.455-0.522)^{2}+(0.524-$ $0.522)^{2}+(0.246-0.522)^{2}+(0.522-0.522)^{2}+(0.743-0.522)^{2}+$ $\left.(0.594-0.522)^{2}\right)=0.025$,

As a result, the population standard deviation is given by:

$\sigma_{\mathrm{x}}=\sqrt{ } \sigma_{\mathrm{x}}^{2}=\sqrt{ } 0.025=0.157$.

The next step (step 5) is determine the $\sigma$ levels $(1 \sigma, 2 \sigma$, or $3 \sigma$ ), and must be determined by the DM. in this section, we considered the all of the suggested formulas (in other words, $1 \sigma, 2 \sigma$, and $3 \sigma$ ), to assign each alternative to one of the predefined categories, as follows. Now, we determine the upper bound and lower bound values for $\mathrm{k}$ classes, by using the proposed method (step 6), as follows:

- $\sigma=1, \mu_{\mathrm{x}}=0.522, \sigma_{\mathrm{x}}=0.157$ :

$$
\begin{gathered}
X>0.522+1(0.157) \\
0.522 \leq X \leq 0.522+1(0.157) \\
0.522-1(0.157) \leq X<0.522 \\
X<0.522-1(0.157)
\end{gathered}
$$

- $\sigma=2, \mu_{\mathrm{x}}=0.522, \sigma_{\mathrm{x}}=0.157$ :

$$
X>0.522+2(0.157)
$$

$0.522+1(0.157) \leq \mathrm{X} \leq 0.522+2(0.157)$

$0.522 \leq \mathrm{X}<0.522+1(0.157)$

$0.522-1(0.157) \leq X<0.522$

$\mathrm{X}<0.522-1(0.157)$ 
- $\sigma=3, \mu_{\mathrm{x}}=0.522, \sigma_{\mathrm{x}}=0.157$ :

$$
\mathrm{X}>0.522+3(0.157)
$$

$0.522+2(0.157) \leq \mathrm{X} \leq 0.522+3(0.157)$

$0.522+1(0.157) \leq X<0.522+2(0.157)$

$0.522 \leq \mathrm{X}<0.522+1(0.157)$

$0.522-1(0.157) \leq \mathrm{X}<0.522$

$\mathrm{X}<0.522-1(0.157)$

In the final step (step 7), we compare the obtained values of alternatives (step 3) with the reference values (step 6), then assigning each alternative to one of the predefined categories, as follows.

For instance, for $\sigma=1$,

Have:

\begin{tabular}{lcc}
$\mathrm{A}_{i}$ & $\mathrm{C}_{i}^{*}$ & Category (or class) \\
\hline $\mathrm{S} 1$ & 0.656 & 2 \\
S2 & 0.355 & 4 \\
S3 & 0.739 & 1 \\
S4 & 0.391 & 3 \\
S5 & 0.455 & 3 \\
S6 & 0.524 & 2 \\
S7 & 0.246 & 4 \\
S8 & 0.522 & 2 \\
S9 & 0.743 & 1 \\
S10 & 0.594 & 2
\end{tabular}

To state the obvious, all the suppliers are classified, class 1 turns out to be the best performance, and class 4 would be the worst performance. For instance, supplier 5 belong to class 3 , hence it is greater than the lower bound of class 3 but less than its upper bound.

A comparison of the test results is given in table 2 and figure 2 .

Table 2. Comparison results, for three $\sigma$ levels

\begin{tabular}{|l|c|c|c|c|}
\hline Alternative & Rating & $\sigma=1$ & $\sigma=$ & $\sigma=3$ \\
\cline { 3 - 5 } & $\left(\mathrm{C}_{\mathrm{i}}^{*}\right)$ & Class & Class & Class \\
\hline S1 & 0.656 & 2 & 3 & 4 \\
\hline S2 & 0.355 & 4 & 5 & 6 \\
\hline S3 & 0.739 & 1 & 2 & 3 \\
\hline S4 & 0.391 & 3 & 4 & 5 \\
\hline S5 & 0.455 & 3 & 4 & 5 \\
\hline S6 & 0.524 & 2 & 3 & 4 \\
\hline S7 & 0.246 & 4 & 5 & 6 \\
\hline S8 & 0.522 & 2 & 3 & 4 \\
\hline S9 & 0.743 & 1 & 2 & 3 \\
\hline S10 & 0.594 & 2 & 3 & 4 \\
\hline
\end{tabular}

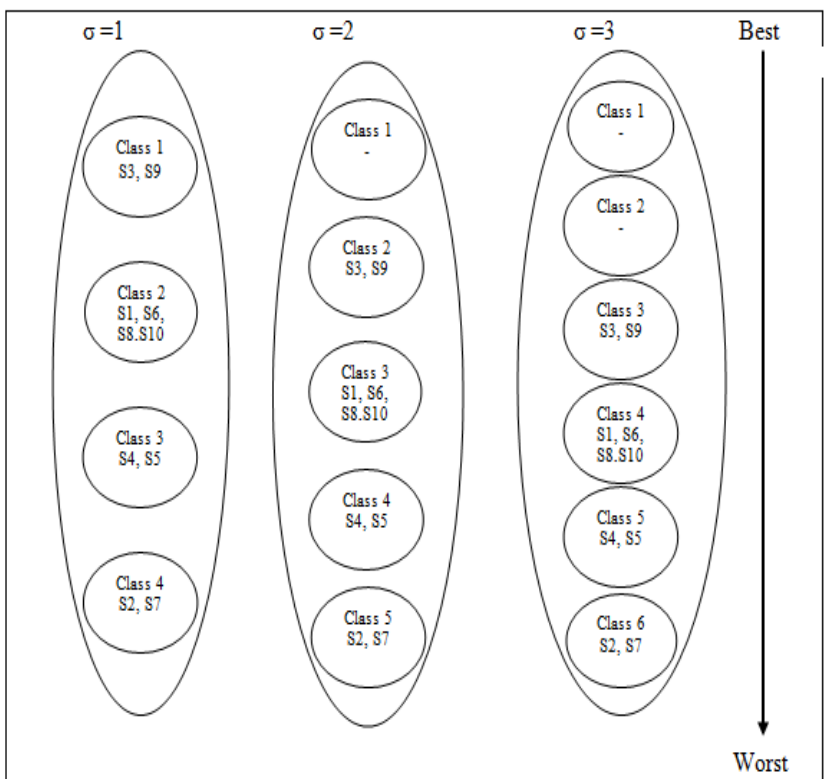

Fig.2: Comparison results, for three $\sigma$ levels

\section{Findings}

In summary, the main findings of this study are as follows.

As seen from table 2 and figure 2; for $\sigma=1$, suppliers S3 and S9 belong to class 1, suppliers S1, S6, S8, and S10 belong to class 2, suppliers S4 and S5 belong to class 3, and suppliers S2 and S7 matches with class 4.

Another important point to observe is that, none of the suppliers matches with classes 1 and class 1 and 2 at the $\sigma=$ 2 and $\sigma=3$ levels, respectively (see table 2 and figure 2). From another perspective, it seems that, supplier S3 and S9 have not very well performance too, and may need to improve in their performance.

On the other side, according to the viewpoint proposed by Wang (2007), one evaluating procedure is to examine the stability of an MCDM methods mathematical process by checking the validity of its proposed ranking. Since, the validation of the proposed method was performed by comparing it with the other existing models. (i.e., AHPSort: Ishizaka, Pearman, and Nemery, 2012; TOPSIS-Sort: Sabokbar, Hosseini, Banaitis, and Banaitiene, 2016; and AHP-K-GDSS: Ishizaka, Lolli, Gamberini, Rimini, and Balugani, 2017).

In this section, with no intention to describe the whole procedure, we shall only point to the starting (the initial data used in previous published articles) (table 3 ) and final results (table 4-6). 
Table 3. Initial data used in previous published articles

\begin{tabular}{|l|c|c|c|c|c|c|}
\hline \multirow{2}{*}{$\begin{array}{l}\text { Altern } \\
\text { ative }\end{array}$} & $\begin{array}{c}\text { Ishizaka et al. } \\
(2012)\end{array}$ & $\begin{array}{c}\text { Sabokbar et } \\
\text { al. (2016) } \\
\text { method }\end{array}$ & $\begin{array}{c}\text { Ishizaka et al. } \\
\text { method }\end{array}$ & \multicolumn{2}{c|}{ method } \\
\cline { 2 - 7 } & $\begin{array}{c}\text { Priorit } \\
\text { y }\end{array}$ & $\begin{array}{c}\text { Cla } \\
\text { ss }\end{array}$ & $\begin{array}{c}\text { Priori } \\
\text { ty }\end{array}$ & $\begin{array}{c}\text { Cla } \\
\text { ss }\end{array}$ & $\begin{array}{c}\text { Priorit } \\
\text { y }\end{array}$ & $\begin{array}{c}\text { Cla } \\
\text { ss }\end{array}$ \\
\hline A1 & 0.900 & 1 & 0.548 & 2 & 7.73 & 3 \\
\hline A2 & 0.900 & 1 & 0.527 & 2 & 7.10 & 3 \\
\hline A3 & 0.894 & 1 & 0.494 & 3 & 8.71 & 3 \\
\hline A4 & 0.809 & 1 & 0.706 & 1 & 8.14 & 3 \\
\hline A5 & 0.791 & 1 & 0.532 & 2 & 7.48 & 3 \\
\hline A6 & 0.715 & 1 & 0.454 & 3 & 8.03 & 3 \\
\hline A7 & 0.577 & 1 & 0.443 & 3 & 7.70 & 3 \\
\hline A8 & 0.386 & 2 & 0.459 & 3 & 7.88 & 3 \\
\hline A9 & 0.332 & 2 & 0.525 & 2 & 7.78 & 3 \\
\hline A10 & 0.300 & 2 & 0.497 & 3 & 8.50 & 3 \\
\hline A11 & 0.252 & 2 & 0.472 & 3 & 8.54 & 3 \\
\hline A12 & 0.100 & 2 & 0.505 & 3 & 8.53 & 3 \\
\hline A13 & - & - & 0.643 & 2 & 8.49 & 3 \\
\hline A14 & - & - & 0.522 & 2 & 10.24 & 2 \\
\hline A15 & - & - & 0.526 & 2 & 10.31 & 2 \\
\hline A16 & - & - & 0.501 & 3 & 9.96 & 3 \\
\hline A17 & - & - & 0.463 & 3 & 12.32 & 1 \\
\hline A18 & - & - & 0.505 & 3 & 8.94 & 3 \\
\hline A19 & - & - & 0.582 & 2 & 7.74 & 3 \\
\hline A20 & - & - & 0.440 & 3 & 8.91 & 3 \\
\hline A21 & - & - & 0.543 & 2 & 9.90 & 3 \\
\hline A22 & - & - & 0.845 & 1 & 9.45 & 3 \\
\hline A23 & - & - & - & - & 10.01 & 3 \\
\hline A24 & - & - & - & - & 11.36 & 2 \\
\hline A25 & - & - & - & - & 7.75 & 3 \\
\hline A26 & - & - & - & - & 7.69 & 3 \\
\hline A27 & - & - & - & - & 141.69 & 2 \\
\hline A28 & - & - & - & - & 12.10 & 1 \\
\hline A29 & - & - & - & - & 11.68 & 2 \\
\hline A30 & - & - & - & - & 8.41 & 3 \\
\hline A31 & - & - & - & - & 10.27 & 2 \\
\hline A32 & - & - & - & - & 10.60 & 2 \\
\hline A33 & - & - & - & - & 9.58 & 3 \\
\hline A34 & - & - & - & - & 9.35 & 3 \\
\hline & & & & & & \\
\hline
\end{tabular}

Table 4. Comparison results for $\sigma=1^{*}$, for example 1 (Ishizaka et al. [2012] method)

\begin{tabular}{|l|c|c|}
\hline $\begin{array}{l}\text { Class } \\
\left(\mathrm{C}_{\mathrm{i}}\right)\end{array}$ & $\begin{array}{c}\text { The proposed } \\
\text { method }\end{array}$ & $\begin{array}{c}\text { Ishizaka, Pearman, and } \\
\text { Nemery (2012) method }\end{array}$ \\
\hline $\mathrm{C}_{1}$ & $\mathrm{~S} 1, \mathrm{~S} 2, \mathrm{~S} 3, \mathrm{~S} 4, \mathrm{~S} 5, \mathrm{~S} 6$ & $\mathrm{~S} 1, \mathrm{~S} 2, \mathrm{~S} 3, \mathrm{~S} 4, \mathrm{~S} 5, \mathrm{~S} 6, \mathrm{~S} 7$ \\
\hline $\mathrm{C}_{2}$ & - & $\mathrm{S} 8, \mathrm{~S} 9, \mathrm{~S} 10, \mathrm{~S} 11, \mathrm{~S} 12$ \\
\hline $\mathrm{C}_{3}$ & $\mathrm{~S} 7$ & - \\
\hline $\mathrm{C}_{4}$ & $\begin{array}{c}\mathrm{S} 8, \mathrm{~S} 9, \mathrm{~S} 10, \\
\mathrm{~S} 11, \mathrm{~S} 12\end{array}$ \\
\hline
\end{tabular}

* . Notice, here, due to the comparison capability between the proposed approach and existing Methods (based on the category numbers), $\sigma=1$ for all examples are used.
Table 5. Comparison results for $\sigma=1^{*}$, for example 2 (Sabokbar et al. [2016] method)

\begin{tabular}{|c|c|c|}
\hline $\begin{array}{l}\text { Class } \\
\left(\mathrm{C}_{\mathrm{i}}\right)\end{array}$ & $\begin{array}{c}\text { The proposed } \\
\text { method }\end{array}$ & $\begin{array}{c}\text { Sabokbar, Hosseini, } \\
\text { Banaitis, and Banaitiene } \\
\text { (2016) method }\end{array}$ \\
\hline $\mathrm{C}_{1}$ & $\begin{array}{c}\mathrm{S} 1, \mathrm{~S} 4, \mathrm{~S} 13, \mathrm{~S} 19, \mathrm{~S} \\
21, \mathrm{~S} 22\end{array}$ & S4,S22 \\
\hline $\mathrm{C}_{2}$ & - & $\begin{array}{c}\mathrm{S} 1, \mathrm{~S} 2, \mathrm{~S} 5, \mathrm{~S} 9, \mathrm{~S} 13, \mathrm{~S} 14, \mathrm{~S} 1 \\
5, \mathrm{~S} 19, \mathrm{~S} 21\end{array}$ \\
\hline $\mathrm{C}_{3}$ & $\mathrm{~S} 2, \mathrm{~S} 5, \mathrm{~S} 9, \mathrm{~S} 15$ & $\begin{array}{c}\text { S3,S6,S7,S8,S10,S11,S1 } \\
\text { 2,S16,S17, } \\
\text { S18,S20 } \\
\end{array}$ \\
\hline $\mathrm{C}_{4}$ & $\begin{array}{c}\text { S3,S6,S7,S8,S10, } \\
\text { S11,S12,S14, } \\
\text { S16,S17,S18,S20 }\end{array}$ & - \\
\hline
\end{tabular}

Table 6. Comparison results for $\sigma=1^{*}$, for example 3 (Ishizaka et al. [2017] method)

\begin{tabular}{|c|c|c|}
\hline $\begin{array}{l}\text { Class } \\
\left(\mathrm{C}_{\mathrm{i}}\right)\end{array}$ & $\begin{array}{l}\text { The proposed } \\
\text { method }\end{array}$ & $\begin{array}{c}\text { Ishizaka, Lolli, Gamberini, } \\
\text { Rimini, and Balugani } \\
\text { (2017) method }\end{array}$ \\
\hline $\mathrm{C}_{1}$ & $\begin{array}{c}\mathrm{S} 17, \mathrm{~S} 24, \mathrm{~S} 27, \mathrm{~S} 28, \\
\text { S29 }\end{array}$ & $\mathrm{S} 17, \mathrm{~S} 28$ \\
\hline $\mathrm{C}_{2}$ & $\begin{array}{c}\text { S14,S15,S16,S21, } \\
\text { S22,S23,S31, } \\
\text { S32,S33,S34 }\end{array}$ & $\begin{array}{c}\mathrm{S} 14, \mathrm{~S} 15, \mathrm{~S} 24, \mathrm{~S} 27, \mathrm{~S} 29, \mathrm{~S} 31 \\
\mathrm{~S} 32\end{array}$ \\
\hline $\mathrm{C}_{3}$ & $\begin{array}{l}\mathrm{S} 1, \mathrm{~S} 3, \mathrm{~S} 4, \mathrm{~S} 5, \mathrm{~S} 6, \mathrm{~S} \\
\text { 7,S8,S9,S10,S11, } \\
\mathrm{S} 12, \mathrm{~S} 13, \mathrm{~S} 18, \mathrm{~S} 19, \\
\mathrm{~S} 20, \mathrm{~S} 25, \mathrm{~S} 26, \mathrm{~S} 30\end{array}$ & $\begin{array}{c}\mathrm{S} 1, \mathrm{~S} 2, \mathrm{~S} 3, \mathrm{~S} 4, \mathrm{~S} 5, \mathrm{~S} 6, \mathrm{~S} 7, \mathrm{~S} 8, \mathrm{~S} \\
\text { 9,S10,S11, } \\
\mathrm{S} 12, \mathrm{~S} 13, \mathrm{~S} 16, \mathrm{~S} 18, \mathrm{~S} 19, \mathrm{~S} 20, \\
\mathrm{~S} 21, \mathrm{~S} 22, \\
\mathrm{~S} 23, \mathrm{~S} 25, \mathrm{~S} 26, \mathrm{~S} 30, \mathrm{~S} 33, \mathrm{~S} 34\end{array}$ \\
\hline $\mathrm{C}_{4}$ & $\mathrm{~S} 2$ & - \\
\hline
\end{tabular}

As you can see from above results (table 4-6), it seems that, the proposed approach provides consistent results to existing methods. However, the best performance alternative (in other words, alternatives in class 1), derived from the proposed model and other existing methods is identical, but the remaining alternatives changes their classes. In addition, these results implicitly indicate the effectiveness of the proposed models. On the other side, some of the existing bias between two models (the proposed approach and existing methods) results, may be due to differences in the number of classes between the models. While, the proposed method has 4 classes (for $\sigma$ $=1$ ), the existing models have 2,3 , and 3 categories for example 1, 2, and 3 respectively.

\section{Conclusion}

In sum, Multi-Criteria Decision Making (MCDM) models allow applying choice, ranking, and sorting problems. However, choice and ranking problems are the ones most commonly weighted in MCDM, the literature 
weakly consider sorting problem. Therefore, the focus of this paper is on sorting problems. More specifically, this paper combines MCDM methods with Chebyshev's theorem to sort suppliers into predefined ordered categories in the supply chain context. Meanwhile, in the literature, several solutions for the above problem are proposed. But, in this paper, different from other works, which put more focused on the extension of new models, this studies attempt to suggest a general framework using the Chebyshev's inequality to transform the results of traditional MCDM models from ranking format to sort mode. In continuation, we present three Chebyshev's-based formulas based on the $\sigma$ levels (in other words, falling within one/ two, or three standard deviations of the mean, or $\sigma=1, \sigma=2$, and $\sigma=3$, respectively) to combine MCDM with the sort. The attractiveness of these approaches is that we do not have to modify the existing MCDM methods. Finally, a numerical example in supplier selection context is given to illustrate the feasibility and practability of the proposed MCDM-Sorting method. According to the results, we can find the suppliers 3 and 9 belong to class 1(the best class), and suppliers 2 and 7 matches with class 4 (the worst class). Another important point to observe is that, none of the suppliers matches with classes 1 , and 1 and 2 at the $\sigma=2$ and $\sigma=3$ levels, respectively. It seems that, above mentioned suppliers have not very well performance too, and may need to improve their performance. In addition, the validation of the proposed method was performed by comparing it with the other existing models (i.e., AHP-Sort, TOPSIS-Sort, and AHPK-GDSS). As a result, the proposed method provides consistent results to existing methods. However, the best alternative (in other words, alternatives in class 1) derived from two models is identical, but the remaining alternatives changes their classes. The findings of this paper indicate the effectiveness of the proposed model.

The advantages of the proposed model are:

1. The proposed method is straightforward and the algorithm is clear. Hence, we believe that the mechanism of proposed method is reasonable.

2. The attractiveness of the proposed model is that; we do not have to modify the conventional MCDM models.

3. The proposed approach makes full use of decision information and does not require the additional data from DMs (Decision Makers).

In sum, the proposed method in this paper ensures transparency in the decision process.

Future research could use the new methods suggested here in different managerial issue (i.e., classifying voters or decision makers into several groups with difference importance level in social choice or group decision making respectively, clustering in data mining environment, employee performance assessment, market segmentation, benchmarking, etc.) to illustrate the models generalizability.

\section{Reference}

[1] Amidan, B. G., Ferryman, T. A., and Cooley, S. K. (2005). Data outlier detection using the Chebyshev theorem. Conference paper in IEEE Aerospace conference proceedings. April 2005. doi: 10.1109/AERO.2005.1559688.Source: IEEE Explore, 1-6.

[2] Arabzad, S. M., Ghorbani, M., Razmi, J., and Shirouyehzad, H. (2014). Employing fuzzy TOPSIS and SWOT for supplier selection and order allocation problem. Int $\mathrm{J}$ Adv Manuf Technol, DOI: 10.1007/s00170-014-6288-3.

[3] Araz, C. and Ozkarahan, I. (2005). A multi-criteria sorting procedure for financial classification problems: the case of business failure risk assessment. Conference, intelligent data engineering and automated learning-IDEAL 2005, $6^{\text {th }}$ international conference Brisbane, Australia, July 6-8, 2005, Proceedings, 563-570.

[4] Ayhan, M. B. (2013). A fuzzy AHP approach for supplier selection problem: A case study in a Gearmotor company. International Journal of Managing value and Supply Chains, 4(3), 1-11.

[5] Birnbaum, M. H. (1998). Measurement-judgment and decisionmaking. Academic Press, San Diego, USA.

[6] Belton, V. and Stewart, T. J. (2002). Multiple criteria decision analysis-An integrated approach. Springer Science+ Business Media Dordrecht.

[7] Bouyssou, D. and Merchant, T. (2007a). An axiomatic approach to noncompensatory sorting methods in MCDM I: the case of two categories. European Journal of operational research, 178(1), 217 245.

[8] Bouyssou, D. and Merchant, T. (2007b). An axiomatic approach to noncompensatory sorting methods in MCDM II: more than two categories. European Journal of operational research, 178(1), 246276.

[9] Chen, Y. (2006). Multiple criteria decision analysis: classification problems and solutions. PhD thesis, Supervisor: K. W. Hipel and M. Kilgour, University of waterloo, Canada.

[10] Corrente, S., Greco, S., and Slowinski, R. (2016). Multiple criteria Hierarchy process for ELECTRE Tri methods. European Journal of operational research, 252(2016), 191-203.

[11] Damart, S., Dias, L. C., and Mousseau, V. (2007). Supporting groups in sorting decisions: methodology and use of a multi-criteria aggregation/ Disaggregation in DSS. Decision Support Systems, 43(4), 1464-1475.

[12] Dias, J., Figueira, J., and Roy, B. (2008). ELECTRE Tri-C: A multiple criteria sorting method based on central reference actions. 2008. hal-00281307V2. University Paris Dauphine, CAHIER DU LAMSADE, 274, 2008, 1-32.

[13] Dias, J. A., Figueira, J., and Roy, B. (2012). A multiple criteria sorting method where each category is characterized by several reference actions: the ELECTRE Tri-nC method. European Journal of operational research, 217(2012), 567-579.

[14] Dias, L. C. and Mousseau, V. (2003). IRIS: A DSS for multiple criteria sorting problems. Journal of Multi-Criteria decision Analysis, 12(2003), 285-298.

[15] Dizaji, L. Y. and Khanmohammadi, S. (2016). A new multi-criteria decision making based on fuzzy-TOPSIS theory. Journal of Advances in Computer Engineering and Technology, 2(4), 39-48.

[16] Doumpos, M. and Zopounidis, C. (2018). Disaggregation approaches for multi-criteria classification: An overview, 99. 77-78. in: preference Disaggregation in multi criteria decision analysis, Essay in honor of Yannis Siskos, Editor: N. Matsasinis \& E. Grigorondis, Springer International Publishing AG, Part of Springer Nature 2018.

[17] Dunn, D. S. (2001). Statistics and data analysis for the behavioral sciences. McGraw-Hill companies, Inc., Newyork.

[18] Fallahpour, A. (2016). Development of multi-criteria decisionmaking model for supplier selection using Gene expression 
programming. $\mathrm{PhD}$ thesis, Supervisor: Dr. Ollugu and Dr. Sitinurmaya, Faculty of Engineering University of MALAYA, Kualalampur.

[19] Frej, E. A., Roselli, L. R. P., Almedia, J. A. D., and Almedia, A. T. D. (2017). A multi-criteria decision model for supplier selection in a food industry based on FITradeoff method. Mathematical Problems in Engineering, Vol. 2017, Article ID: 4541914, 1-9.

[20] Hwang, C. L. and Yoon, K. (1981). Multiple attribute decision making: methods and applications, Springer-verlag, Berlin.

[21] Ishizaka, A., Lolli, F., Gamberini, R., Rimini, B., and Balugani, E. (2017). AHP-K-GDSS: A new sorting method based on AHP for group decisions. Proceedings of the international conference on modeling and applied simulation 2017, ISBN 978-88-97999-91-1; Bruzzone, Defelice, Frjdman, Lougo, massei and Solis Eds., 1-5.

[22] Ishizaka, A. and Nemery, P. (2013). Multi-criteria decision analysismethods and software. John Willy \& Sons, Ltd.

[23] Ishizaka, A. and Nemery, PH. (2014). Assigning machines to incomparable maintenance strategies with ELECTRE Sort. Omega, 2014, Advance online Publications, 10.10161j.omega.2014.03.006.

[24] Ishizaka, A., Pearman, C., and Nemery, P. (2012). AHP Sort: An AHP based method for sorting problems. International Journal of Production Research, 50(17), 4767-4784.

[25] Kamal, M., Gupta, S., and Raina, A. A. (2018). Fuzzy multiobjective supplier selection problem in a supply chain. World Scientific News, 100(2018), An International Scientific Journal, $165-183$

[26] Karasakal, E. and Aker, P. (2017). A multi-criteria sorting approach based on data envelopment analysis for R\&D project selection problem. Omega, 73(2), 79-92.

[27] Karsu, O. (2016). Approaches for inequity-averse sorting. Computer \& Operations research, 66(2016), 67-80.

[28] Lourenco, R. P. and Costa, J. P. (2004). Using ELECTRE Tri outranking method to sort MOMILP nondominated solutions. European Journal of operational research, 153(2004), 271-289.

[29] Memmah, M. M., Turion, B. Q., and Rolland, A. (2014). Multicriteria sorting methods to select virtual peach ideotypes. International Journal of Multi Criteria Decision Making, 4(4), 348366.

[30] Mousseau, V. and Slowinski, R. (1998). Inferring ELECTRE Tri model from assignment examples. Journal of Global Optimization, 12(1998), 157-174.

[31] Pelissari, R., Amor, S. B., and Oliveira, M. C. (2019). A multicriteria decision sorting model for pharmaceutical suppliers classification under multiple uncertainties. In book: Pharmaceutical supply chains-Medicines shortages, doi: 10.1007/978-3-030-153984_17.

[32] Rao, R. V. (2007). Decision making in the manufacturing environment, using graph theory and fuzzy multiple attribute decision-making methods. Springer-Verlag, London.

[33] Ravindran, A. (2008). Operations Research and Management science Handbook. Taylor \& Francis group, LLC.

[34] Rocha, C. and Dias, L. C. (2008). An algorithm for ordinal sorting based on ELECTRE with categories defined by examples. J Glob Optim, 42(2008), 255-277.

[35] Roostaee, R., Izadikhah, M., Lotfi, F. H., and Malkhalifeh, M. R. (2012). A multi-criteria intuitionistic fuzzy group decision making method for supplier selection with VIKOR method. International journal of Fuzzy System Applications, 2(1), 1-17.
[36] Roszkowska, E. (2011). Multi-criteria decision-making models by applying the TOPSIS method to crisp and interval data. Multiple Criteria Decision Making/ University of Economics in Katowice 6, 200-230, 2011.

[37] Roszkowska, E. (2013). Rank ordering criteria weighting methods A comparative overview. Optimum, Studia Ekonomiczne, NR 5(65), 14-33.

[38] Roy, B. (1996). Multicriteria methodology for decision aiding. Translator: M. R. McCord, Springer Science+Business Media Dordrecht.

[39] Saaty, T L. and Daj, E. (2015). When is a decision making evaluation multi-criteria decision making methods. International Journal of Information Technology \& Decision Making, IJITDM-D15-000031R1, 1-18.

[40] Sabokbar, H. F., Hosseini, A., Banaitis, A., and Banaitiene, N. (2016). A novel sorting method TOPSIS-Sort: An application for Tehran environmental quality evaluation. Business administration and Management, 2(XIX), 87-.

[41] Seifbarghy, M., Gilklayeh, A. P., \& Alidoost, M. (2011). A comprehensive fuzzy multiobjective supplier selection model under price brakes and using interval comparison matrices. Journal of Industrial and Systems Engineering, 4(4), 224-244.

[42] Shih, H. S., Shyur, H. J., and Lee, E. S. (2007). An extension of TOPSIS for group decision making. Mathematical and Computer Modelling, 45(2007), 801-813.

[43] Sobrie, O. (2016). Learning preferences with multi-criteria models. Universite Paris-Saclay; Universite de Mous, 2016, English, NNT: 2016 SACLC057.Supervisor: prof. M. Pirlot.

[44] Tabar, A. A. and Charkhgard, H. (2012). Supplier selection in supply chain management by using ANP and fuzzy TOPSIS. International Journal of Applied Physics and Mathematics. 2(6), 458-461.

[45] Tayeb, S., Ahcene, B., Omar, P. J. S., and Mouloud, B. K. (2007) 'Equipment selection by numerical resolution of the Hessian matrix and Topsis algorithm', Asian Journal of Information Technology, Vol. 6, No. 1, pp.81-88.

[46] Tervonen, T., Figueira, J., Lahdelma, R., Dias, J. A. and Salminen, P. (2009). A stochastic method for robustness analysis in sorting problems. European Journal of operational research, 192(2009), 236-242.

[47] Walpole, R. E., Myers, R. H., Myers, S. L., and Ye, K. (2016). Probability \& statistics for engineers \& Scientists. Prentice Hall, PEARSON.

[48] Wang X. (2007). study of ranking irregularities when evaluating alternatives by using some ELECTRE methods and proposed new MCDM method based on Regret and Rejoicing. MSc. Thesis, supervisor: E. Triantaphyllou, Louisiana State University, USA.

[49] Xu, Z. (2015). Uncertain multi attribute decision-making methods and applications. Springer-Verlag, Berlin Heidelberg.

[50] Yue, Z. (2013 ${ }_{\mathrm{a}}$ ). Group decision making with multi-attribute interval data. Information Fusion, 14(2013), 551-561.

[51] Yue, Z. (2013 $)$. An avoiding information loss approach to group decision making. Applied Mathematical Modelling, 37(2013), 112126.

[52] Zopounidis, C. and Doumpos, M. (2002). Multi-Criteria classification and sorting method: A literature review. European Journal of operational research, 138(2002), 229-246. 